\title{
Justiça e ponderação de direitos fundamentais
}

\author{
Justice and weighting of fundamental rights
}

Lourdes Pasa Albrecht ${ }^{1}$

Resumo: O objetivo deste texto é avaliar a perspectiva da efetivação da justiça nos casos concretos de colisão de direitos fundamentais na teoria da ponderação construída por Robert Alexy. A inter-relação entre os juízos ponderativos e a justiça da decisão permeia todo trabalho de investigação. Para tanto, busca elucidar os desdobramentos da ponderação como atividade argumentativa racional como mote de realização da justiça, utilizando-se das reflexões sobre justiça baseadas em Chaïm Perelman. O propósito decisivo do estudo é evidenciar que a ponderação deve seguir formas e regras de argumentação jurídica racional e critérios próprios do procedimento da ponderação (sopesamento), demonstrando que o problema não está na ponderação, mas na sua correta aplicação numa situação concreta de direitos fundamentais colidentes, considerada sua natureza de princípios.

Palavras-chave: Justiça. Colisão de direitos fundamentais. Ponderação. Argumentação.

\begin{abstract}
The objective of this text is to evaluate the perspective of the effectiveness of justice in the concrete cases of collision of fundamental rights in the theory of weighting constructed by Robert Alexy. The interrelationship between weighing judgments and the justice of decision permeates all research work. To do so, it seeks to elucidate the unfolding of weighting as a rational argumentative activity as a motto for the realization of justice, using reflections on justice based on Chaïm Perelman. The decisive purpose of the study is to highlight that the weighting must follow forms and rules of rational legal argumentation and criteria of the weighting procedure, showing that the problem is not in the weighting but in its correct application in a concrete situation of fundamental rights their nature as principles.
\end{abstract}

Keywords: Justice. Collision of fundamental rights. Weighting. Argumentation.

\section{INTRODUÇÃO}

Este artigo trata da questão da efetivação da justiça nos casos concretos de colisão de direitos fundamentais com o uso da ponderação de Robert Alexy, considerada a natureza de princípios desses direitos e concebidos em sua teoria como mandamentos de otimização que podem ser cumpridos em diferentes

\footnotetext{
${ }^{1}$ Doutoranda PPG-Filosofia PUCRS. E-mail: lourdes.pasa@gmail.com.
} 
graus. O objetivo é compreender de que maneira a ponderação é uma atividade argumentativa e como tal deve obedecer às regras da argumentação racional, da ponderação e à regra de justiça, utilizando-se das reflexões sobre justiça baseadas em Chaïm Perelman. A proposta do trabalho consiste em demonstrar que a ponderação pode ser racional e também que sua aplicação na resolução de casos concretos de direitos fundamentais em colisão pode ser justificada racionalmente, propiciando uma decisão judicial correta e, portanto, justa. $\mathrm{O}$ propósito decisivo da investigação é evidenciar que a ponderação como atividade argumentativa deve seguir formas e regras de argumentação jurídica racional e critérios próprios do procedimento da ponderação ou sopesamento, expondo, ainda, que o problema não está na ponderação, mas na sua correta aplicação.

Não obstante, a ponderação como método jurídico (balancing process) para solução de casos concretos de colisão de direitos fundamentais, embora inegável reconhecimento no âmbito internacional na prática e na teoria da jurisdição constitucional, tem provocado objeções no sentido de que o método não ofereceria parâmetros racionais para o sopesamento de direitos fundamentais. Isso implicaria no risco de incorrer em juízos irracionais, conduzindo à irracionalidade e ao subjetivismo do julgador, além de ameaçar a força em geral dos direitos fundamentais ao serem transformados em mandamentos de otimização.

A controvérsia de que a ponderação seria uma atividade irracional e o fato de que ela levaria ao enfraquecimento dos direitos fundamentais são razões para se levantar a questão sobre sua racionalidade e se as críticas são procedentes. Nessa perspectiva, o presente texto pretende explorar se no uso disseminado da ponderação pelos tribunais constitucionais há a realização da justiça no caso concreto na resolução de colisões entre direitos fundamentais. O problema que se coloca, portanto, é saber se é possível obter uma decisão justa com o uso da ponderação num caso concreto de direitos fundamentais em colisão ou se o método da ponderação representa um simples instrumento ilusório de racionalidade e justiça.

O foco da tarefa aqui incidirá, pois, na elucidação e análise dos desdobramentos da ponderação como atividade argumentativa racional e os elementos de sua fundamentação como método para resolução de direitos fundamentais em situação concreta de colisão, no contexto da teoria dos 
princípios idealizada por Alexy, verificando sobretudo a realização da justiça no caso concreto decidido.

\section{PONDERAÇÃO E ARGUMENTAÇÃO RACIONAL}

A teoria dos direitos fundamentais de Roberto Alexy é uma teoria dos princípios e da estrutura dos direitos subjetivos, influenciada pelo reconhecimento do constitucionalismo contemporâneo como modelo jurídico ideal. A tese central é que os direitos fundamentais têm natureza de princípios e são mandamentos de otimização que podem ser cumpridos em diferentes graus. Para Alexy, um sistema jurídico adequado é composto por regras, princípios e procedimentos. Com efeito, um dos pontos fundamentais para uma teoria adequada sobre restrição, colisão e o papel dos direitos fundamentais no sistema jurídico é a distinção entre regras e princípios. Ela serve de sustentáculo da possibilidade e dos limites da racionalidade no âmbito de tais direitos e, nesse sentido, considerada por Alexy uma das colunas mestras de sua teoria dos direitos fundamentais. Sustenta o autor que sem essa distinção não pode haver nem uma teoria adequada sobre as restrições a direitos fundamentais, nem satisfatória sobre colisões, tampouco uma teoria suficiente sobre o papel desses direitos no sistema jurídico.

A característica de um sistema jurídico constituído exclusivamente por um modelo de regras é a relação de vinculação e de abertura (alcance interpretativo das formulações abertas das normas de direitos fundamentais). Manifesta-se alto grau de vinculação quando a regra pode simplesmente indicar a solução de um caso. Contudo, na hipótese de o sistema jurídico não dispor de uma regra clara e preestabelecida para a decisão de um caso concreto abrir-se-ia espaço à discricionariedade judicial. Um modelo puro de princípios, por outro lado, substituiria vinculação por sopesamento e, com isso, haveria perda de clareza normativa e univocidade para a Constituição (ALEXY, 2014, p.123). Por essas razões, deve-se considerar a forma de um modelo combinado de regras e princípios $^{2}$, caminho possível para superar tal problema.

\footnotetext{
${ }^{2}$ A vinculação dos dois níveis (regras e princípios) surge quando é incluída na formulação da norma constitucional uma cláusula restritiva com a estrutura de princípios sujeita a sopesamentos, onde são atribuídos, de um lado, o grau ou a intensidade da não-satisfação de um
} 
O principal traço distintivo da teoria dos princípios de Alexy é a estrutura que as normas de direitos fundamentais garantem. As regras garantem direitos (ou impõem deveres) definitivos. Se um direito é garantido por uma norma-regra, esse direito deve ser realizado totalmente se a regra é aplicável ao caso concreto. Já os princípios garantem direitos (ou impõem deveres) prima facie e sua realização é apenas parcial. O caminho entre o direito prima facie até o direito definitivo passa pela definição de uma regra, isto é, sempre que um princípio for uma razão decisiva para um juízo concreto de dever ser, esse princípio é o fundamento de uma regra a qual representa uma razão definitiva para esse juízo concreto. Princípios em si mesmo nunca são razões definitivas.

Enquanto para Dworkin o modo de aplicação diferenciado entre ambas as espécies de normas no caso de conflito de regras e de colisão de princípios reside no fato de que as regras são aplicáveis à maneira do tudo ou nada (all-or-nothing fashion), isto é, possuem apenas dimensão de validade, pois dados os fatos que uma regra estipula ou a regra é válida e, portanto, aceita, ou não é válida, não contribuindo para a decisão (DWORKIN, 2010, p. 39). Dito de outro modo: as regras simplesmente se aplicam ou não se aplicam aos casos concretos para os quais foram instituídas. Ou se uma regra é válida e absolutamente aplicável a um caso dado, então ela "obriga", determinando de forma conclusiva o resultado jurídico ou a consequência.

Os princípios, ao contrário das regras, não determinam obrigatoriamente a decisão a ser tomada, mas contêm os fundamentos que apontam a favor de uma ou outra decisão, embora não prescindam passar por um processo de interpretação sobre as condições presentes no caso, pois pode haver outros princípios que apontem uma direção oposta. Além disso, eles possuem uma dimensão de peso ou importância ausente nas regras, sendo essa dimensão uma parte integrante do conceito de princípio. No caso de colisão entre princípios

princípio e, de outro, o grau de importância da satisfação do outro princípio. Disso extrai-se a regra constitutiva para sopesamentos: "Quanto maior for o grau de não-satisfação ou de afetação de um princípio, tanto maio terá que ser a importância da satisfação do outro" (ALEXY, 2014, p. 141, 167). Na expressão de Streck, o modelo de princípios constitucionais ingressa no cenário jurídico para superar o paradigma da dedução, provocado pelo império das regras em um mundo de subsunções e deduções que não mais fazem do que reforçar a subjetividade (discricionariedade) do intérprete. São princípios que constituem o sentido da regra na situação hermenêutica gerada no Estado Democrático de Direito. "Não é um princípio geral do direito, um princípio bíblico, um princípio (meramente) político” (STRECK, 2008, p. 303). 
aquele que vai resolver o conflito no caso concreto tem que levar em conta a força relativa de cada um. O de força maior supera o outro sem no entanto eliminá-lo do ordenamento jurídico. O princípio afastado, embora não logrando determinar a decisão, sobreviverá intacto ao ser utilizado noutros casos em que possa prevalecer em concorrência com qualquer outro princípio de menor peso (DWORKIN, 2010, p.42-43).

Não obstante considere demasiado simples o modelo teorizado por Dworkin de que as regras, se válidas, devem ser aplicadas do modo tudo ou nada 3 enquanto os princípios apenas contêm razões que indicam uma direção, Alexy parte do pressuposto similar ao de Dworkin de que a distinção entre regras e princípios é uma distinção qualitativa e não meramente de grau ou quantitativa. Complementou essa ideia e desenvolveu principalmente a concepção de princípios como mandamentos de otimização, a qual representa o núcleo essencial da ponderação.

Nesse contexto, Alexy diz que a base do argumento de princípio forma a distinção entre regras e princípios, apontando, em síntese, que:

Regras são normas que ordenam, proíbem ou permitem algo definitivamente ou autorizam a algo definitivamente. Elas contêm em dever definitivo. Quando os seus pressupostos estão cumpridos, produz-se a consequência jurídica. Se não se quiser aceitar esta, deve ou declarar-se a regra como inválida e, com isso, despedi-la do ordenamento jurídico, ou, então, inserir-se uma exceção na regra e, nesse sentido, criar uma nova regra. A forma de aplicação de regras é a subsunção. Princípios contêm, pelo contrário, um dever ideal. Eles são mandamentos a serem otimizados. Como tais, eles não contêm um dever definitivo, mas somente um dever prima-facie (...). Eles colidem com outros princípios. A forma de aplicação ideal para eles é, por isso, a ponderação. Somente a ponderação leva do dever-prima-facie ideal ao dever real e definitivo (ALEXY, 2008a, p.37).

Princípios são, assim, normas que ordenam que algo seja realizado na maior medida possível diante das possibilidades fáticas e jurídicas existentes. As condições jurídicas referem-se a possível colisão entre os princípios envolvidos. Segundo Alexy, essa colisão entre princípios deve ser resolvida, no caso concreto, por meio de um sopesamento para se chegar a um resultado ótimo. Alcançar um

\footnotetext{
3 Não obstante, a aplicação das regras ao modo tudo ou nada também precisa "de um processo prévio - de interpretação que demonstre quais as consequências que serão implementadas" (ÁVILA, 2001, p.14).
} 
resultado ótimo é definir qual dos interesses conflitantes abstratamente no mesmo nível tem maior peso.

Isso nos permite inferir que para se chegar a um resultado ótimo faz-se necessário, muitas vezes, restringir a realização de um dos princípios. Ou seja, um princípio limita as possibilidades jurídicas da concretização do outro. No caso concreto essa situação consiste no estabelecimento de uma relação de precedência condicionada entre os princípios, fixando condições sob as quais um princípio tem precedência em face do outro. Sob outras condições é possível que a questão seja resolvida de maneira oposta. Essas condições são dadas pela lei da colisão, formulada por Alexy, que reza: “As condições sob as quais um princípio tem precedência em face do outro constituem o suporte fático de uma regra que expressa a consequência jurídica do princípio de precedência” (ALEXY, 2014, p.99).

A lei da colisão reflete, portanto, o caráter dos princípios como imperativos de otimização que devem ser realizados na melhor medida possível, de acordo com a situação fática e o contexto jurídico respectivos, indicando a inexistência de relação absoluta de precedência.

Cumpre assinalar, no entanto, que a tese da otimização foi alvo de inúmeras críticas. Uma das mais importantes objeções foi de Habermas, alegando que o modelo de princípios baseado na otimização retira força dos direitos fundamentais.

Quando princípios colocam um valor, que deve ser realizado de modo
otimizado e quando a medida de preenchimento desse mandamento de
otimização não pode ser extraído da própria norma, a aplicação de tais
princípios no quadro do que é faticamente possível impõe uma
ponderação orientada por um fim. E, uma vez que nenhum valor pode
pretender uma primazia incondicional perante outros valores, a
interpretação ponderada do direito vigente se transforma numa
realização concretizadora de valores, referida a casos (HABERMAS,
2003, p. 315).

A "ponderação orientada por um fim" implicaria perda de solidez dos direitos fundamentais, que só é garantida por meio de uma estrutura deontológica (estrutura de regras). O caráter principiológico demoliria essa proteção. "No caso de uma colisão, todas as razões podem assumir o caráter de argumentos de colocação de objetivos, o que faz ruir a viga mestra introduzida no discurso jurídico pela compreensão deontológica de normas e princípios do direito” (HABERMAS, 2003, p. 321). Além disso, o sopesamento implicaria o 
risco de os direitos fundamentais sofrerem de juízos irracionais, "uma vez que não há medidas racionais para isso, a avaliação realiza-se de modo arbitrário ou irrefletido, seguindo ordens de precedência e padrões consuetudinários" (HABERMAS, 2003, p. 321-322).

Em resumo, Habermas considera que os direitos fundamentais seriam flexibilizados ao serem transformados em mandamentos de otimização e ameaçados de desaparecer em razão do sopesamento irracional. Além do mais, os direitos fundamentais enquanto princípios produziriam seus efeitos por todo sistema jurídico de tal modo a reduzir o espaço de conformação do legislador democraticamente legitimado. Sua atividade esgotar-se-ia na mera constatação daquilo que foi decidido pela constituição, incrementando, assim, indevidamente o ativismo da função jurisdicional 4 .

Nessa perspectiva e considerando a controvérsia de que a ponderação seria uma atividade irracional e enfraqueceria os direitos fundamentais, a questão a ser examinada agora é como são solucionados os casos de colisões de direitos fundamentais à luz da teoria dos princípios de Robert Alexy, com suporte na teoria da argumentação jurídica desenvolvida por ele, promovendo uma interlocução com o pensamento de Chaïm Perelman sobre a argumentação racional que permeia o Direito e a Justiça. Cuida-se também analisar se o método da ponderação aplicável nos casos concretos entre princípios constitucionais colidentes seria sustentável e suas objeções superadas ou seria um mero álibi retórico para o exercício do discricionarismo judicial.

Nesse contexto, a discussão é estabelecida sobre como se aplica a ponderação, que requer um princípio mais abrangente - o princípio da proporcionalidade - e racionalidade da decisão judicial em circunstâncias concretas de colisão de direitos fundamentais 5 , situação que conduz ao próximo passo da análise, a saber, o papel da argumentação racional no cerne estrutural da ponderação no âmbito dos direitos fundamentais.

\footnotetext{
4 Este é o cerne da crítica também de Ernst-Wolfgang Böckenförde, que se refere principalmente à associação entre o sopesamento e o perigo de excesso dos direitos fundamentais, os quais transformar-se-iam em "princípios supremos da ordem jurídica” (ALEXY, 2014, p. 577-578).

5 Na concepção de Vieira de Andrade haverá colisão ou conflito sempre que se deva entender que a Constituição protege simultaneamente dois valores ou bens em contradição numa determinada situação concreta. "A esfera de proteção de um direito é constitucionalmente protegida em termos de intersectar a esfera de outro direito ou de colidir com uma outra norma ou princípio constitucional" (ANDRADE, 2004, p. 321-322).
} 


\section{ESTRUTURA DA PONDERAÇÃO E ARGUMENTAÇÃO NO ÂMBITO DOS DIREITOS FUNDAMENTAIS}

A proposta teórica de Robert Alexy apresenta a proporcionalidade como um sistema estruturante à aplicação e fundamentação das normas de direitos fundamentais que têm caráter de princípios. O significado da distinção entre regras e princípios resulta no entendimento da existência de uma conexão estreita entre a teoria dos princípios e a máxima da proporcionalidade. Isso significa dizer que a natureza dos princípios implica a máxima da proporcionalidade e essa implica aquela. Assim, sustenta o autor, se a natureza dos princípios implica a máxima da proporcionalidade significa que a aplicação do sistema da proporcionalidade requer sejam observadas as suas três máximas parciais que a compõem: (i) da adequação; (ii) da necessidade (mandamento do meio menos gravoso) e (iii) da proporcionalidade em sentido estrito (mandamento de sopesamento propriamente dito).

Os três princípios parciais expressam a ideia de otimização. Os princípios da adequação e da necessidade se ocupam da otimização relativa às possibilidades fáticas. Eles não tratam da ponderação, mas de evitar intervenção em direitos fundamentais que sem custos para outros princípios são evitáveis. Exige-se que o sacrifício de cada um dos princípios ou valores constitucionais seja adequado e necessário à salvaguarda dos outros. Em outras palavras: uma medida é "adequada" se o meio escolhido for apto para atingir o resultado pretendido; "necessária", se entre as disposições disponíveis e igualmente idôneas para promover a realização de um direito fundamental é a que menos intensamente intervém no outro direito fundamental envolvido. Se não atender a esses pressupostos "não chega sequer a existir um verdadeiro conflito" (ANDRADE, 2004, p. 326). Já a máxima da proporcionalidade em sentido estrito, isto é, a exigência de sopesamento, cuida da otimização relativamente às possibilidades jurídicas, que são determinadas sobretudo pelos princípios colidentes. Esse é o âmbito da ponderação (ALEXY, 2008a, p. 132).

Assim, consideradas duas medidas igualmente idôneas para a promoção de um direito fundamental deve ser escolhida aquela que menos acentuadamente intervém em outro direito fundamental. No entanto, a escolha entre uma das duas alternativas não é uma questão das possibilidades fáticas, isto é uma questão para 
o exame da necessidade, mas de possibilidades jurídicas. Trata-se, pois, de uma questão de sopesamento entre os princípios envolvidos ( $\left.\begin{array}{lll}\mathrm{P} 1 & \mathrm{e} & \mathrm{P} 2\end{array}\right)$ proporcionalidade em sentido estrito. "É por isso que, caso até mesmo o meio menos gravoso afete a realização de $P 2$, ao exame da necessidade deve se seguir sempre o exame da proporcionalidade em sentido estrito, isto é, a exigência de sopesamento" (ALEXY, 2014, p. 120).

No entanto, mesmo que uma medida que restrinja um direito fundamental seja adequada e necessária para promoção de um outro direito fundamental, não significa por si só seja proporcional. Para alcançar esse objetivo, segundo Alexy, é necessário o exame da proporcionalidade em sentido estrito, que consiste em um sopesamento entre a intensidade da intervenção em um direito fundamental afetado e a importância da realização do direito fundamental que com ele colide e que fundamenta a medida restritiva. O princípio parcial da proporcionalidade em sentido estrito - a terceira máxima da proporcionalidade - é o campo da ponderação ${ }^{6}$ e diz respeito ao cumprimento do mandamento de otimização em relação as condições jurídicas. O núcleo da ponderação consiste em uma relação de precedência denominada pelo autor de "lei da ponderação" (ou de sopesamento) que encontra sua fórmula elaborada pela fórmula do peso7:

"Quanto maior o grau do não cumprimento ou prejuízo de um princípio, tanto maior deve ser a importância do cumprimento do outro" (ALEXY, 2008a, p. 133$)^{8}$.

A lei da ponderação desmembra-se em duas. A primeira - chamada lei material do sopesamento - diz respeito à fundamentação da intervenção e

\footnotetext{
${ }^{6}$ Segundo articula Rodrigo Bernholdt, a exigência da ponderação surge apenas: "a) quando houver efetivamente uma colisão entre bens jurídicos; b) nessa colisão, não se pondera um bem jurídico contra o outro, mas os fins por ele representados; c) essa finalidade só é determinável a partir dos casos concretos, pois são eles que permitem as concretas modalidades de exercício do direito; d) objetivo da ponderação será estabelecer regras de precedência, que permitirão uma subsunção apenas quando o novo caso tenha semelhança com a situação precedente [...], caso contrário as novas circunstâncias poderão exigir nova ponderação". A partir desses critérios deve servir a exigência de ponderação para a realização de "um trabalho metódico compatível com um Estado Democrático de Direito, afastando-se o espectro do decisionismo, que tanto tem rondado nosso país" (BERNHOLDT, 2015).

7 A fórmula do peso é apresentada por Alexy assim: GPij=IPiC/WPjC. O "G" representa o peso concreto de $P i$ sob as circunstâncias do caso decidido $(C)$, que 'se sempre umpeso relativo, uma vez que ele determina o peso concreto como quociente entre a intensidade da intervenção em $P i$ e a importância concreta do princípio em sentido contrário $P j$. Com isso o peso concreto de $P i$ é o peso concreto de $P i$ em relação a $P j$ (Alexy, 2014, p. 604)

${ }^{8}$ Cf. também (ALEXY, 2014, p. 167; 593-594).
} 
satisfação entre os princípios fundamentais. A segunda - denominada lei epistêmica do sopesamento ou lei da ponderação epistêmica - diz respeito àquilo que abrange a certeza empírica sobre esses juízos de intervenção e satisfação. "Quanto mais pesada for a intervenção em um direito fundamental, tanto maior terá que ser a certeza das premissas nas quais essa intervenção se baseia" (ALEXY, 2014, p. 617). A verificação dos graus de intervenção e satisfação sobre os princípios jurídicos envolvidos (P1 e P2) é avaliada por uma escala de três níveis (modelo triádico) dada pela fórmula do peso. Esses níveis são identificados por meio dos graus leve (l), médio $(m)$ e severo(s) (ALEXY, 2008a, p.133). A partir dessa escala triádica é que o Tribunal Constitucional baliza o sopesamento. A fórmula do peso representaria assim um modo de se organizar o raciocínio do julgador a ser desenvolvido no sopesamento, objetivando clarificar como se realiza seu procedimento em relação aos princípios constitucionais em conflito e tendo a pretensão de se chegar a um resultado por meio de critérios racionais de decidibilidade.

Desse modo, a configuração da "fórmula do peso" idealizada por Robert Alexy importaria a atribuição de graus diferentes ao processo de ponderação entre princípios colidentes como a intensidade de intervenção, o peso abstrato, a certeza das premissas, e a importância da realização (GAVIÃO FILHO, 2010, p. 329). Contudo, a racionalidade da decisão não se esgota na simples atribuição de graus para as variáveis da fórmula peso. Ela exige que sejam apresentadas razões de justificação dos graus atribuídos a cada uma das variáveis, especialmente quanto aos graus de intensidade de intervenção em um princípio e de importância da satisfação do outro princípio, no caso em julgamento. É necessário, portanto, justificar a decisão tomada, fornecendo uma argumentação convincente, indicando a legitimidade das escolhas feitas pelo juiz, professa Perelman. É esta justificação "que, explicitando as razões do dispositivo, deve convencer as partes de que a sentença não resulta uma tomada de posição arbitrária" (PERELMAN, 2004, p. 222). O fato de o julgador não explicitar o grau de intervenção em um direito fundamental ou não expor razões que possibilitem essa identificação não seria uma questão da ponderação e sim de como ela é levada a efeito por aquele que aplica um princípio por meio da ponderação, como demonstra Gavião Filho9.

\footnotetext{
9 Essa constatação apoia-se na jurisprudência do Tribunal Constitucional Federal alemão, na qual a indicação expressa de graus de intensidade (leve, médio e grave) de intervenção nos direitos
} 
Nesse contexto, a proposta teórica de Alexy para aplicação dos direitos fundamentais mediante a máxima da proporcionalidade implicaria a imbricação entre os direitos fundamentais, a ponderação e a argumentação jurídica, enfatizando sobretudo a importância da racionalidade dos juízos de ponderação entre os princípios jurídicos envolvidos num caso concreto de colisão. O grau de racionalidade originar-se-ia da estrutura lógica derivada de juízos referentes à correlação entre intervenção e satisfação dos princípios envolvidos, além da intensidade da confiança sobre as premissas fáticas expressas na fórmula do peso.

Com efeito, é diante da atribuição de juízos de ponderação ao texto constitucional que o direito fixaria a sua conexão necessária com a moral, aproximando a dimensão real do direito (direito posto ou a decisão judicial) à sua dimensão ideal (pretensão de correção). Tal aproximação somente se sustentaria, segundo Alexy, mediante demonstração argumentativa de pretensão de correção obtida pela argumentação jurídica, cujo mote é dar conta das aberturas ou lacunas dos dispositivos constitucionais. Ou seja, seria por meio de correção que o direito mostrar-se-ia substancialmente ligado com a moral discursiva. Nas palavras de Morais, "para que o Direito cumprisse com o elemento moral, ou melhor dizendo, para que representasse a necessária conexão conceitual entre Direito e Moral, deveria ele apresentar a devida pretensão de correção mediante a fundamentação racional de suas decisões” (MORAIS, 2013, p. 85).

Isso deixa reconhecer que no âmbito dos direitos fundamentais o modelo de ponderação de princípios colidentes proporciona um critério que permite vincular a estrutura formal da lei da ponderação com a teoria da argumentação jurídica, que abrange uma teoria da argumentação prática geral (ALEXY, 2014, p. 548). Desse modo, se direitos fundamentais são princípios suscetíveis de colisões, cuja solução demanda pela ponderação, e se decisões judiciais racionais dependem da argumentação, então deve ser estabelecida uma ligação entre ponderação e argumentação. Por sua vez, a questão da certeza na fundamentação no âmbito dos direitos fundamentais leva à relação entre argumentação e decisão.

Nessa perspectiva, o empenho de Robert Alexy foi dotar a atividade de ponderar de critérios de racionalidade, que necessariamente passaria pela

fundamentais é corrente. No Superior Tribunal Federal, diferentemente, é pouco comum a referência expressa a graus de intensidade de intervenção em direitos fundamentais (GAVIÃO FILHO, 2010, p. 309). 
fundamentação racional como condição de legitimidade de adjudicação. A legitimidade da ponderação depende de sua racionalidade, pois quanto mais racional é a ponderação, tanto mais legítimo é o ponderar (ALEXY, 2008a, p. 131). Assim, a decisão que se utiliza da ponderação seria considerada legítima somente se a valoração feita dos princípios jurídicos envolvidos na resolução do caso concreto pudesse ser fundamentada, aspecto que derivaria da qualidade racional desses juízos valorativos. Nessa dimensão, a ligação entre a ponderação e a teoria da argumentação jurídica seria encontrada no momento em que a argumentação pudesse atuar de forma a corrigir e justificar racionalmente a ponderação.

Com efeito, a questão acerca da fundamentação racional das decisões judiciais foi objeto de investigação desenvolvida por Robert Alexy na obra publicada em 1978, intitulada "Teoria da Argumentação Jurídica" (Theorie der juristischen Argumentation). Nesse estudo o autor procurou conciliar especialmente as regras dos discursos práticos gerais de Habermas com as formas de argumentação de Perelman, fundadas no acordo do auditório universal ${ }^{10}$. Para Alexy, há uma confluência entre a concepção do acordo da audiência universal e o consenso de Habermas alcançado sob condições ideais (ALEXY, 2001, p.134). Na perspectiva de Perelman os participantes somente se convenceriam por meio de argumentos racionais. O consenso seria o critério de racionalidade da argumentação. No cerne da sua teoria como teoria normativa da argumentação estaria, portanto, a caracterização de um auditório que pode ser convencido por meios racionais, denominado por Perelman de auditório universal, isto é, àquele constituído por todos os seres dotados de razão. O acordo de parte do auditório universal seria o critério de racionalidade e objetividade na argumentação (PERELMAN; OLBRECHT-TYTECA, 2005, p. 34-35) ${ }^{11}$.

\footnotetext{
${ }^{10}$ Não obstante, Alexy aponta uma certa imprecisão no conceito de auditório universal no tocante à limitação do seu papel normativo na medida que uma audiência só é uma audiência universal para aqueles que a reconhecem como tal. Ou seja, seria "norma somente para aqueles que a aceitam como uma norma". Mas, contemporiza essa ponderação por encontrar uma variante desse conceito baseado no imperativo categórico de Kant: "Você precisa se comportar como se fosse um juiz, cuja ratio decidendi deva fornecer um princípio válido para todos os homens'. A concordância da audiência universal é assim "o acordo de todos os homens razoáveis" (ALEXY, 2001, p.133).

${ }^{11} \mathrm{O}$ acordo do auditório universal, isto é, racionalidade e objetividade, segundo Perelman é o propósito de todos os filósofos: "Os filósofos sempre pretendem dirigir-se a um auditório assim, não por esperarem obter o consentimento efetivo de todos os homens [...], mas por crerem que
} 
Sob a ótica de Habermas o consenso seria alcançado numa condição ideal de fala (paradigma de objetividade e racionalidade), isto é, de total liberdade e simetria entre todos os participantes do discurso, o que eliminaria as distorções sistemáticas da comunicação, garantindo o consenso racional do discurso ${ }^{12}$. As exigências de simetria e liberdade estabeleceriam o conteúdo das regras do discurso racional que Alexy denomina regras da razão. Caracterizam-se, entre outras, pela clareza linguística, não contradição e sinceridade. A finalidade destas regras é a imparcialidade do discurso. As regras do discurso prático geral formam o que Alexy chama de código geral da razão prática, cuja observância assegura a racionalidade da argumentação. E é precisamente a racionalidade que confere universalidade às conclusões obtidas consensualmente.

Nessa premissa, conforme Alexy, o discurso jurídico é um caso especial de discurso prático geral. O ponto comum é que as duas formas de discurso se preocupam com a correção de afirmações normativas. A tese do caso especial consiste num procedimento racional, discursivo e intersubjetivo o qual intenta legitimar decisões propiciando ao Direito correção e justiça. Ela expressa uma conexão necessária entre direito e moral, porque afirma que o discurso jurídico compreende o discurso prático geral e este inclui necessariamente o discurso moral. A exigência de justiça seria a pretensão de correção, mas isso se realiza e daí ser um caso especial - sob o limite do tipo descrito da ordem jurídica vigente, que é a vinculação à lei, ao precedente e à dogmática. Assim, a pretensão de correção compreende o princípio da segurança jurídica e o princípio da justiça.

No âmbito dos direitos fundamentais a base da argumentação pode ser identificada sob as rubricas "lei”, "precedente” e “dogmática” (ALEXY, 2014, p.551). A vinculação à lei é uma vinculação ao texto das disposições de direitos

todos os que compreenderem suas razões terão de aderir às suas conclusões. O acordo de um auditório universal não é, portanto, uma questão de fato, mas de direito. É por se afirmar o que é conforme a um fato objetivo, o que constitui uma asserção verdadeira e mesmo necessária, que se conta com a adesão daqueles que se submetem aos dados da experiência ou às luzes da razão" (PERELMAN, 2005, p. 35).

12 Um exemplo da teoria discursiva de Habermas seria a introdução de procedimentos democráticos na constituição da legislação como expressão da soberania popular. Assim, se discursos "constituem o lugar no qual se pode formar uma vontade racional, a legitimidade do direito apoia-se, em última instância, num arranjo comunicativo: enquanto participantes de discursos racionais, os parceiros do direito devem poder examinar se uma norma controvertida encontra ou poderia encontrar o assentimento de todos os possíveis atingidos. [...] A cooriginariedade da autonomia privada e pública somente se mostra, quando conseguimos decifrar o modelo de autolegislação através da teoria do discurso" (HABERMAS, 2003, p. 138-139). 
fundamentais e à vontade do legislador constituinte. Enquanto que os precedentes "servem para indicar uma ordem objetiva relativa entre critérios de valoração (princípios jurídicos ou valores) que deveriam ser tomados como razões que fundamentam cada decisão” (MORAIS, 2013, p. 97). Alexy indica duas regras fundamentais para utilização dos precedentes: (1) Se é possível usar um precedente favorável ou contrário a uma decisão ele deve ser citado; (2) O ônus argumentativo cabe àquele que pretende afastar o precedente. A argumentação dogmática, por sua vez, complementa a base de argumentação no âmbito dos direitos fundamentais. Ela desempenha um papel importante na justificação das premissas das decisões judiciais de utilização de normas jurídicas.

Assim, a argumentação na esfera dos direitos fundamentais pode ser racional, alicerçada pelo processo discursivo, apresentado por Alexy como um procedimento argumentativo que se ocupa com o atingimento de resultados constitucionalmente corretos, fornecendo à argumentação uma certa estabilidade e uma estrutura racional. À luz dessa intelecção, "vale a ideia de que a razão prática pode ser realizada apenas no âmbito de um sistema jurídico que vincule, de forma racional, argumentação e decisão” (ALEXY, 2014, p. 574).

Desse modo, a decisão que se vale da ponderação nos casos concretos de colisão de direitos fundamentais somente poderia ser considerada legítima e aceita se fundamentada racionalmente, apresentando argumentos que demonstrem a correção exigida pelas proposições jurídicas (forma lógica do argumento jurídico). As razões das proposições seriam o indicativo de sua condição racional, consequentemente o fundamento da sua correção. Assim, a ponderação envolveria um juízo valorativo sobre qual princípio jurídico deveria prevalecer sobre outro num caso concreto. E como todos os juízos esse juízo necessitaria de uma fundamentação por meio de argumentos para que a decisão judicial pudesse expressar sua racionalidade. Logo, se a decisão é racional então ela seria correta. Se correta, seria justa. Exatamente esse é o ponto de análise da próxima e última seção deste artigo acerca da realização da justiça na aplicação da ponderação de princípios concretamente colidentes.

\section{JUSTIÇA, PONDERAÇÃO E ARGUMENTAÇÃO}


O plano de ação aqui é explorar sinteticamente, num primeiro momento, o papel da justiça na abordagem de Chaïm Perelman. Em seguida, apresentar os elementos conectivos entre justiça e argumentação, procurando situar o campo da argumentação e destacar como seu conceito respalda o de justiça perelmaniano em diálogo com a teoria da ponderação de Alexy. Por fim, examinar se a aplicação da ponderação na solução de hard cases, mais especificamente de casos concretos de colisão de direitos fundamentais promoveria uma decisão justa conforme o fim do direito - a promoção da justiça.

A concepção de justiça de Perelman parte do pressuposto que o uso prático da razão pode embasar uma decisão por meio de técnicas de argumentação e persuasão. Para isso o autor utilizou-se da dialética de matriz aristotélica como instrumento de promoção de um acordo sobre valores. Apresentou uma lógica dos juízos de valor capaz de estabelecer critérios objetivos e universais (válidos para todos) que possibilitasse uma solução racional para problemas que envolvessem juízos valorativos. Assim, ao estabelecer a técnica que regulamenta o raciocínio argumentativo, Perelman instaurou a ligação da argumentação e a noção de justiça.

Com efeito, a noção de justiça como dever de concretização dos direitos fundamentais plasmados numa ordem constitucional democrática, notadamente nas situações em que dois (ou mais) direitos fundamentais concorrem em igualdade hierárquica, ao mesmo tempo que um "cede" espaço ao outro no caso concreto de colisão a priori provocaria ao "perdedor" uma sensação de injustiça que poderia pôr em dúvida a percepção e o sentido de justiça na solução da controvérsia judicial in concreto.

Partindo-se desse pressuposto, impende indagar qual seria a fórmula que atendesse na prática o almejado ideal de justiça que fosse aceito por todos. Para Perelmenan, a fórmula ideal de justiça parte da extração de elementos comuns entre seis principais concepções de justiça por ele examinadas ${ }^{13}$ que pudessem identificar critérios de aplicação universal da noção de justiça que fossem aceitos por todos. Denominada justiça formal ou abstrata, essa fórmula foi definida por

\footnotetext{
13 As seis fórmulas mais correntes da justiça concreta: (i) A cada qual a mesma coisa; (ii) A cada qual segundo seus méritos; (iii) A cada qual segundo suas obras; (iv) A cada qual segundo suas necessidades; (v) A cada qual segundo sua posição; e (vi) A cada qual segundo o que a lei lhe atribui (PERELMAN, 2002, p. 9). Para a análise de Perelman de cada uma dessas noções onde explicita suas principais características, ver (PERELMAN, 2002, p. 9 e ss.).
} 
Perelman como um princípio formal de ação onde todos os seres de uma mesma categoria essencial devem ser tratados da mesma forma (PERELMAN, 2002, p. 19). O vínculo do fundamento de justiça é, portanto, a igualdade de tratamento a todos aqueles que a regra não distingue. Em situações concretas quando é a lei positiva que fornece critérios de aplicação da regra formal a regra de justiça se torna regra de direito, exigindo sejam tratados todos os que forem semelhantes perante a lei. "A regra de direito é a regra de justiça acompanhada de modalidades determinadas pela vontade do legislador. A ação conforme à regra de direito é justa porque aplica corretamente a lei" (PERELMAN, 2002, p. 160).

A justiça formal, porém, não pode limitar-se à aplicação correta de uma regra (qualquer), porque ser justo é aplicar a regra justa, pois dizer que um ato é formalmente justo é diferente de enunciar que a regra é justa. $O$ critério que vai dizer se a regra é justa está no princípio que fundamenta a regra, isto é a regra adquire essa qualidade se estiver de acordo com o princípio que a fundamenta (WEBER, 2008, p. 227). Se a lei for injusta, diz Perelman, aplica-se o princípio da justificação dos valores que a fundamenta. Para o autor, justificar princípios ou valores é fazer escolhas, concedendo-lhes primazia na condução de uma ação ou decisão. A escolha daqueles que devem ser aplicados é uma escolha racional, ganhando legitimidade por meio de sua fundamentação.

Justificar a decisão tomada é fornecer uma argumentação convincente das escolhas feitas pelo juiz. Segundo Perelman, é essa justificação específica do raciocínio jurídico que explicitando as razões do dispositivo da sentença deve convencer as partes de que a sentença não deriva de uma manifestação arbitrária. A justificação implica, portanto, apelo à razão que nos termos perelminianos se funda no discurso da argumentação onde são apresentados argumentos calcados em valores que sejam universalizáveis, situação que eliminaria a arbitrariedade.

Nessa linha, MacCormick compartilha da visão segundo a qual a justificação das decisões requer a sua universalização ou a demonstração de que tais decisões seriam aceitáveis se universalizadas. $O$ ato de justificar "envolve $o$ estabelecimento de boas bases racionais para o que se faz e, dessa maneira, depende de uma concepção de racionalidade e de um compromisso com a racionalidade assim concebida" (MacCORMICK, 2008, p. 198). À evidência, a distância que separa o texto do intérprete não é obstáculo a ser superado, mas aliado na empreitada interpretativa, buscando por meio da argumentação 
racional uma decisão justa ao caso concreto, conforme o fim do Direito. Na expressão de Amartya Sen, “a argumentação racional é central para a compreensão da justiça mesmo em um mundo que inclui muita 'desrazão'; na verdade, ela pode ser especialmente importante em um mundo assim” (SEN, 2011, p. 21).

A exigência de uma escolha racional entre valores no desenvolvimento da fundamentação da decisão vai ao encontro, em grande medida, da proposta teórica de Alexy, especialmente na formulação valorativa dos direitos fundamentais catalogados nas Constituições contemporâneas, onde as teorias de valores se manifestam com força na jurisprudência constitucional. Não obstante, a teoria valorativa dos direitos fundamentais foi alvo de muitas objeções de ordem filosófica, metodológica e dogmática. As objeções metodológicas foram objeto de nosso maior interesse investigativo por concentrar seus ataques contra a concepção de ordem hierarquizada de valores e contra o sopesamento. Quanto as objeções acerca da hierarquização de valores Alexy refere a Constituição alemã, cujo ponto culminante foi a decisão do caso Lüth pelo Tribunal Constitucional Federal (BVerGE 7, 198) ${ }^{14}$. No desenvolvimento da fundamentação da decisão, a ordem de valores foi qualificada pelo tribunal como "hierarquia de valores", no âmbito da qual um "sopesamento" se fez necessário (ALEXY, 2014, p. 154).

Alexy fixou tratar essas objeções especificamente nos valores relevantes para uma decisão no âmbito dos direitos fundamentais. Isso porque, segundo ele, quando se fala em ordem hierarquizada de valores só poderia fazer-se menção a tais valores, esclarecendo que do ponto de vista dos direitos fundamentais seria possível discutir quais valores seriam relevantes e quais não seriam. Todavia, o

\footnotetext{
${ }_{14}$ Em 1958, o Tribunal Constitucional alemão julgou o caso Lüth, admitindo que um particular utilizasse direitos fundamentais contra outro particular. O Tribunal Constitucional decidiu a favor de Lüth, justificando que haveria uma "ordem objetiva de valores" na Constituição, e todo o ordenamento jurídico seria irradiado por essa ordem, incluindo-se as relações entre particulares. Na decisão do caso Lüth, mesmo que o Tribunal Constitucional Federal tenha partido do pressuposto de que 'os direitos fundamentais são destinados, em primeira instância, a proteger a esfera de liberdade do indivíduo contra intervenções dos poderes públicos', isto é, de que são "direitos de defesa do cidadão contra o Estado", ele adita, na mesma decisão, que '[i]gualmente correto é o fato de que a Constituição, que não pretende ser uma ordenação axiologicamente neutra, (...) também estabeleceu, na seção dedicada aos direitos fundamentais, uma ordem objetiva de valores (...). Esse sistema de valores, em cujo centro se encontra o livre desenvolvimento da personalidade humana e de sua dignidade no seio da comunidade social, deve valer, como decisão constitucional fundamental, para todos os ramos do direito' (ALEXY, 2014, p. 154).
} 
autor reconhece que uma ordenação de valores ou princípios juridicamente relevantes só seria possível numa ordem constitucional flexível, que pode surgir por meio de preferências prima facie em favor de determinado princípio ou valor e de uma rede de decisões concretas sobre preferências. A primeira seria obtida, por exemplo, quando se pressupõe uma carga argumentativa em favor da liberdade individual ou de igualdade. A segunda seria alcançada por meio da jurisprudência do Tribunal Constitucional Federal. Ambas estão intimamente ligadas ao sopesamento (ALEXY, 2014, p. 163).

A objeção à ideia de sopesamento parte do pressuposto de que ele não seria um modelo passível de controle racional, uma vez que valores e princípios não disciplinam sua própria aplicação. Por isso, os críticos dizem, como Habermas, por exemplo, 15 que o sopesamento seria irracional, ficando ao arbítrio do julgador, abrindo espaço para o subjetivismo e decisionismo. No entanto, Alexy afirma que as críticas são improcedentes porque a teoria dos princípios sustenta a tese segundo a qual o sopesamento não é um procedimento que conduz em todo e qualquer caso a um resultado único e inequívoco (ALEXY, 2014, p. 594). Para afastar de forma cabal as divergências e demonstrar que a ponderação é um procedimento racional, Alexy apresenta o modelo fundamentado de sopesamento, segundo o qual a eleição de preferências condicionadas dos princípios colidentes passa por um processo de fundamentação (a escolha feita é expressa em fundamentos).

Conforme o modelo fundamentado defendido por Alexy o resultado do sopesamento consiste em um enunciado de preferências condicionadas que de acordo com a lei de colisão corresponde uma regra de decisão diferenciada, não sendo, portanto, um procedimento por meio do qual um interesse é realizado às custas de outro de forma irrefletida. Assim, garante o autor, restariam afastadas definitivamente as controvérsias de que a ponderação seria um procedimento abstrato ou generalizante. O próprio conceito de princípio decorre a comprovação de que os sopesamentos não são uma questão de tudo ou nada, mas uma tarefa de otimização (ALEXY, 2014, p. 173). A tarefa de otimização [prescrita pela

\footnotetext{
${ }^{15}$ Habermas faz um alerta precisamente para o perigo dos juízos irracionais na medida em que um tribunal constitucional adota a doutrina da ordem de valores tomando-a como base de sua prática de decisão, porque, neste caso, "os argumentos funcionalistas prevalecem sobre os normativos" (HABERMAS, 2003, 321-322).
} 
concepção de princípio como mandamento de otimização] consiste em determinar as corretas relações de prioridade condicionais (ALEXY, 2000, p. 297). A restrição a um direito fundamental, portanto, somente seria admissível se, no caso concreto, fosse atribuído aos princípios colidentes um peso maior que aquele dado ao princípio de direito fundamental em questão (ALEXY, 2014, p. 296).

Não obstante, a questão é saber o que é levado em conta pelo julgador para justificar a gradação do peso no cumprimento de princípios para afastar o subjetivismo. A margem de subjetividade do juiz poderia manifestar-se justamente no momento de aferir o peso do princípio ou do direito fundamental que irá prevalecer sobre outro que conflita no caso decidindo. Ao proferir a decisão é possível o juiz mascarar seus argumentos, fundamentando a decisão segundo seus critérios próprios de justiça

Tal situação pode ocorrer também de a ponderação ser utilizada como referencial teórico para resolução de colisão entre direitos fundamentais em outro ordenamento jurídico sem qualquer tipo de contextualização (a chamada recepção) ou mesmo sem qualquer rigor na observância do procedimento da ponderação. No método proposto por Alexy a ponderação leva à formação de uma regra, que será aplicada ao caso por subsunção. Essa regra regerá um novo caso semelhante se por meio de uma subsunção as características do novo caso se incluírem no campo da aplicação da regra. Os tribunais brasileiros, contudo, "utilizam esse conceito como se fosse um enunciado performático, uma espécie de álibi teórico capaz de fundamentar os posicionamentos mais diversos" (STRECK, 2014, p. 60).

Para embasar essa realidade, consideramos como espelho resultados de uma pesquisa doutoral de Fausto Morais sobre 189 casos julgados pelo Supremo Tribunal Federal (STF) ${ }^{16}$ que fazem referência à proporcionalidade. Entre outras imprecisões, a tese constatou que em nenhuma decisão examinada foi construída a lei da colisão que permitiria ao juiz apresentar a justificação racional da decisão, fator essencial para Alexy ao combate do decisionismo judicial. A referência feita

16 O marco temporal dos casos analisados na tese intitulada Hermenêtica e Pretensão de Correção: uma revisão crítica da aplicação do princípio da proporcionalidade pelo Supremo Tribunal Federal compreendeu o período de julho de 2002 a julho de 2012. Decisões e suas conclusões, ver (MORAIS, 2013, p. 141 e ss.; 286 e ss.). 
às colisões não se restringiu aos princípios jurídicos, nem foi observada a sua condição de mandamentos de otimização, identificando que os casos concretos "promoviam colisão tanto entre princípios, quanto entre bens, interesses, valores e Direitos Fundamentais” (MORAIS, 2013, p. 296-297). Grande parte dessas decisões, segundo Morais, não foram precedidas pela análise das submáximas da adequação e necessidade. A aplicação da proporcionalidade pelo STF seria apenas "um simulacro da teoria de Robert Alexy" (MORAIS, 2013, p. 297).

Por todo o examinado, evidencia-se que a solução das colisões de direitos fundamentais reclama por ponderação. Decisões judiciais em geral e das cortes constitucionais em particular dependem de argumentação racional, isto é as proposições normativas que sustentam o resultado do sopesamento devem ser fundamentadas, estabelecendo-se, nessa perspectiva, um vínculo entre argumentação, ponderação e justiça. Assim, a correta aplicação do método da ponderação para a resolução dos casos concretos que envolvem princípios fundamentais colidentes se mostraria apropriado, pois capaz de conduzir o julgador a uma decisão racionalmente fundamentada.

\section{CONCLUSÃO}

Esse estudo mostra que o procedimento da ponderação para resolução de colisões de direitos fundamentais é racional se aplicado corretamente. A ponderação se desenvolve dentro de um processo racional de argumentação, mediado pelos julgamentos fundamentados dos tribunais constitucionais. Por conseguinte, a decisão que faz uso da ponderação para solução da colisão entre princípios no caso concreto é um método racional e eficaz para a realização da justiça.

Não obstante, conforme análise aqui empreendida mostrar-se incontornável um certo grau de subjetividade do julgador revela-se possível reduzir seus riscos seguindo-se os elementos estruturantes da teoria da ponderação os quais incorporam critérios racionais de decidibilidade na sua aplicação. A ponderação enuncia o que e como deve ser fundamentado racionalmente.

A prova de racionalidade da ponderação é extraída de suas regras próprias e das regras da argumentação jurídica. As razões das proposições jurídicas são 
indicativo de racionalidade da ponderação e, consequentemente, fundamento de sua correção e aceitação racional amparada em argumentos. O juízo de ponderação deve apresentar a justificação que dá sustentáculo racional à decisão. No caso concreto, a ponderação impõe-se no exato momento de se estabelecer o peso de cada direito fundamental em situação de colisão. Ela se apoia na lei da ponderação e na lei da colisão.

De forma resumida, a lei da ponderação encontra sua elaboração na fórmula do peso que indica como deve ser realizada a ponderação. Quanto maior o grau ou o peso de não cumprimento ou prejuízo de um princípio, tanto maior deve ser a importância do cumprimento do outro. A lei da colisão prescreve seja estabelecida uma relação de precedência, conforme o peso concreto do princípio determinado pela fórmula do peso, ordenando a prioridade de um princípio sobre o outro em situação de colisão, considerando-se as circunstâncias do caso concreto.

Princípios são mandamentos de otimização, que podem ser satisfeitos em diferentes graus. A medida de sua satisfação depende das possibilidades fáticas e jurídicas. O âmbito das possibilidades jurídicas é determinado pelos princípios e regras colidentes. A otimização é o sopesamento que aponta a relação de prioridade dos princípios colidentes envolvidos. A fórmula do peso indica que a ponderação deve ser realizada por meio da verificação de todas as circunstâncias do caso concreto, tornando possível ao julgador analisar qual dos direitos fundamentais em colisão tem primazia. Na tomada da decisão o juiz deve apresentar razões que justifiquem os graus atribuídos aos princípios colidentes. A razão argumentativa possibilita a justificação da primazia.

A ponderação é um procedimento argumentativo. A argumentação é uma atividade orientada por regras, alicerçada na teoria discursiva do direito. No âmbito dos direitos fundamentais o discurso é um procedimento argumentativo que se ocupa com resultados constitucionalmente corretos. A pretensão de correção compreende o princípio da segurança jurídica e o princípio da justiça. O primeiro impõe comprometimento com aquilo que é criado de modo autoritativo e socialmente efetivo.

O princípio da justiça exige que a decisão seja moralmente correta, no sentido de abranger tanto facticidade quanto idealidade. Na qualidade de representação argumentativa (discursiva) a jurisdição constitucional é uma 
expressão da dialética do real e do ideal, isto é próprio da dupla natureza do direito. Logo, a dúplice natureza do direito se manifesta na argumentação jurídica. As razões das proposições jurídicas são indicativo de racionalidade da ponderação e, consequentemente, fundamento de sua correção e aceitação racional amparada em argumentos.

Desse modo, a argumentação na esfera dos direitos fundamentais é racionalmente estruturada sobre a base da lei, do precedente e da dogmática e por meio das regras da argumentação prática geral e da argumentação jurídica, vinculando racionalmente argumentação e decisão judicial.

Assim, a decisão judicial que segue rigorosamente os passos do procedimento da ponderação para solução de direitos fundamentais colidentes seria correta e, portanto, justa.

\section{REFERÊNCIAS}

ALBRECHT, Lourdes Pasa. Justiça: entre a colisão de Direitos Fundamentais e ponderação. 2016. Dissertação (Mestrado em Filosofia). Escola de Humanidades da Pontifícia Universidade Católica do Rio Grande do Sul, Porto Alegre, 2016.

ALEXY, Robert. Teoria dos direitos fundamentais. Tradução Virgílio Afonso da Silva. 2. ed. São Paulo: Malheiros Editores, 2014.

. Constitucionalismo discursivo. Tradução Luís Afonso Heck. 2. ed. Porto Alegre: Livraria do Advogado, 2008a.

Teoria da argumentação jurídica: a teoria do discurso racional como teoria da justificação jurídica. Tradução Zilda Hutchinson Schild Silva. São Paulo: Landy Editora, 2001.

On the structure of legal principles. In: Ratio Juris, v. 13, n. 3, p. 294304, Setembro de 2000.

ANDRADE, José Carlos Vieira de. Os direitos fundamentais na constituição portuguesa de 1976. 3. ed. Coimbra: Almedina, 2004. 
ÁVILA, Humberto. A distinção entre princípios e regras e a redefinição do dever de proporcionalidade.In: Revista Diálogo Jurídico, Salvador, CAJ, Centro de Atualização Jurídico, v. I, n. 4, jul. 2001. Disponível em: <http://www.direitopublico.com.br>. Acesso em: 19 abr. 2018.

BERNHOLDT, Rodrigo Meyer. Das possibilidades da ponderação no novo CPC e de sua não vinculação a um método específico. In: Informativo Migalhas, n. 3.641, 25 jun. 2015. Disponível em: <http://www.migalhas.com.br./depeso/16,MI222185,71043>. Acesso em: 27 abr. 2018.

DWORKIN, Ronald. Levando os direitos a sério. Tradução Nelson Boeira. 3. ed. São Paulo: WMF Martins Fontes, 2010.

GAVIÃO FILHO, A. P. (2010). Colisão de direitos fundamentais, argumentação e ponderação. 2010. Tese (Doutorado em Direito). Faculdade de Direito da Universidade Federal do Rio Grande do Sul (UFRGS), Porto Alegre, 2010.

HABERMAS, Jürgen. Direito e democracia: entre facticidade e validade. 2. ed. Rio de Janeiro: Tempo Brasileiro, 2003.

MacCORMICK, Neil. Retórica e o estado de direito. Tradução Conrado Hübner Mendes. Rio de Janeiro: Elsevier, 2008.

MORAIS, Fausto Santos de. Hermenêutica e pretensão de correção: uma revisão crítica da aplicação do princípio da proporcionalidade pelo Supremo Tribunal Federal. 2013. 346. Tese (Doutorado em Direito), Faculdade de Direito, Universidade do Vale do Rio dos Sinos, São Leopoldo, 2013.

PERELMAN, Chaïm; OLBRECHTS-TYTECA, Lucie. Tratado da argumentação: a nova retórica. Tradução Maria Ermantina Galvão. 2. ed. São Paulo: Martins Fontes, 2005.

PERELMAN, Chaïm. Lógica jurídica. Tradução Virgínia K. Pupi. 2. ed. São Paulo: Martins Fontes, 2004.

SEN, Amartya. A ideia de justiça. Tradução Denise Bottmann, Ricardo Doninelli Mendes. São Paulo: Companhia das Letras, 2011. 
ALBRECHT, Lourdes Pasa. Justiça e ponderação de direitos fundamentais | 65 WEBER, Thadeu. Justiça e poder discricionário. In: Direitos fundamentais \& justiça. N. 2, Jan./Mar., 2008. Disponível em: <http://www.dfj.inf.br/Arquivos/PDF Livre/2 Doutrina 12>. Acesso em: 30 jul. 2018. 